\title{
Author Correction: Dad and Mom Bods? Inferences of Parenting Ability from Bodily Cues
}

\author{
Donald F. Sacco $^{1}$ (D) $\cdot$ Kaitlyn Holifield ${ }^{1} \cdot$ Kelsey Drea ${ }^{1} \cdot$ Mitch Brown $^{2} \cdot$ Alicia Macchione $^{1}$
}

Published online: 1 February 2020

(C) Springer Nature Switzerland AG 2020

\section{Author Correction: Evolutionary Psychological Science https://doi.org/10.1007/s40806-020-00229-x}

The original version of this article contained an error in how the results of a prior research study were reported. The 3rd sentence under the section "Inferred Social Value of Male and Female Features" should read as "For example, men valuate women's waist-to-hip ratio in attractiveness, which although not associated with fertility is associated with women's maximum reproductive value (Lassek and Gaulin 2018; Singh et al. 2010)." The citations in this correction correspond to the these references:

The online version of the original article can be found at https://doi.org/ 10.1007/s40806-020-00229-x

Donald F. Sacco

Donald.Sacco@usm.edu

1 School of Psychology, The University of Southern Mississippi, 118 College Drive \#5025, Hattiesburg, MS 39406, USA

2 Fairleigh Dickinson University, Teaneck, NJ 07666, USA

\section{References}

Lassek, W. D., \& Gaulin, S. J. C. (2018). Do the low WHRs and BMIs judged most attractive indicate higher fertility? Evolutionary Psychology, 16, 1-16.

Singh, D., Dixson, B. J., Jessop, T. S., Morgan, B., \& Dixson, A. F. (2010). Cross-cultural consensus for waist-hip ratio and women's attractiveness. Evolution and Human Behavior, 31, 176-181.

Publisher's Note Springer Nature remains neutral with regard to jurisdictional claims in published maps and institutional affiliations. 